lection Naukova Prace Harkivskogo universitetu Povitryanih Forces, 3 (48), 108-111.

4. Fox, J. (2009). Concrete Staining Adds Color to Flooring. Sioux City Journal.

5. Primachenko, A. S., Meteljuk, V. A., Moskalenko, A. A., Tiholaz, E. V., Trofimova, I. A. (2016). High-quality decorative concrete. Resursoekonomni materials, structures, buildings and facilities. Rivne National University of Water Management and Nature, 32, 98-104.

6. Nasvik, J. (2006). Using Metakaolin in Decorative Concrete Mixes. Concrete Construction, 51 (8), 52.

7. Kuzmina, V. P. (2000). The pigments for the paint industry. J. Building materials, 10, 46-47.

8. Trofimov, V. I., Kramar, L. I. (2010). Analysis of the synthetic pigments properties for architectural concrete. Bulletin of the South Ural Technical University, 15, 36-38.

9. Kramar, L. I., Trofimov, V. I., Dobrovol'skij, I. P. (2012). Iron oxide pigments for decorative concrete. Bulletin of the South Ural Technical University, 17, 51-55.

10. Dudar, I. N. (1989). Hardening of cement paste under pressure. J. Cement, 7, 10-14.
11. Sokolov, V. G. (1994). The durability of the pressed concrete. J. Building materials, 10, 22-26.

12. Krivenko, P., Cao, H. L., Weng, L. Q., Kavalerova, E. (2014). Mineralogical Aspects of Durable Geocement Matrix Formation - Role of Alkali. Advanced Materials Research, 1004-1005, 1523-1530. doi: 10.4028/www.scientific.net/amr. 1004-1005.1523

13. Chiara, L. (2009-2010). Sviluppo di nuovi materiali geopolimerici per l'applicazione nel settore dei beni culturali. Alma Mater Studiorum - Università di Bologna. Anno Accademico, 131.

14. F. Pacheco-Torgal (Ed.) et. al. (2014). Handbook of Alkali-activated Cements, Mortars and Concretes. Woodhead Publishing in Elsevier, Oxford, UK. doi: 10.1016/B978-178242-276-1.50032-0

15. Guzij, S. G. (2011). Geocementy i materialy na ih osnove. Strategija kachestva v promyshlennosti i obrazovanii. Bolgarija, 1, 86-89.

16. Guzii, S. G., Krivenko, P. V., Kirichok, V. I., Kravchenko, A. V., Manak, Ja. (2013). Research rheology modified geocement. Construction materials and sanitary equipment: Proc.-Tech. Coll., 48, 89-93.

Рекомендовано к публикации д-р техн. наук Гои В. I. Дата надходження рукопису 26.07.2016

Гузий Сергей Григорьевич, кандидат технических наук, старший научный сотрудник, Научноисследовательский институт вяжущих веществ и материалов им. В. Д. Глуховского, Киевский национальный университет строительства и архитектуры, пр. Воздухофлотский, 31, г. Киев, Украина, 03037 E-mail: sguziy@ukr.net

Теренчук Светлана Анатольевна, кандидат физико-математических наук, доцент, Киевский национальный университет строительства и архитектуры, пр. Воздухофлотский, 31, г. Киев, Украина, 03037 E-mail: terenchuksa@ukr.net

\title{
УДК 658.7:656.2
}

DOI: 10.15587/2313-8416.2016.78520

\section{РАЗРАБОТКА ПРИНЦИПОВ СОЗДАНИЯ РЕГИОНАЛЬНЫХ ТРАНСПОРТНО- ЛОГИСТИЧЕСКИХ КЛАСТЕРОВ В УКРАИНЕ}

\author{
(C) Е. С. Алешинский, В. В. Мещеряков, Л. В. Белоус
}

В статье представлен способ повышения конкурентоспособности железных дорог. Приведены модели развития железнодорожного транспорта с негосударственной собственностью. Был проведен анализ основных моделей функционирования кластеров в мировой практике. Рассмотрен кластерный подход к организачии перевозочного прочесса, приведены свойства кластера и их классификация, схема построения, транспортно-логистического кластера (ТЛК)

Ключевые слова: транспортно-логистический кластер, конкурентоспособность, кластерный подход, диверсификация, инфраструктура, факторы производства, глобализация

The article presents a method to increase competitiveness of railways. The models of the development of railway transport with non-state property are shown. An analysis of the main models of functioning clusters in the world is conducted. The cluster approach to the organization of the transportation process is considered. The properties of the cluster and their classification, scheme for the construction of transport and logistics cluster (TLC) are shown

Keywords: transport and logistics cluster, competitiveness, cluster approach, diversification, infrastructure, factors of production, globalization

\section{1. Введение}

На протяжении последних лет Украина направляет основные усилия к внедрению общемировой модели рыночных отношений во все сферы жизни страны. Но большинство отраслей народного хозяйства не отвечают требованиям качества развитых стран. Железнодорожный транспорт - не исключение.

Сегодня транспортный сектор экономики Украины в целом удовлетворяет только базовые по- 
требности экономики и населения в перевозках. Уровень безопасности, показатели качества и эффективности перевозок грузов, энергоэффективности, техногенной нагрузки на окружающую среду не отвечают современным требованиям. Остается низким уровень сервисного обслуживания клиентов, недостаточно используется имеющийся транзитный потенциал и выгодное географическое положение страны.

Наблюдается отставание в развитии транспортной инфраструктуры, транспортно-логистических технологий, мультимодальных перевозок, уровня контейнеризации, что обуславливает высокую долю транспортных затрат в себестоимости продукции. Также все больше обусловливается снижение доли железных дорог на рынке грузовых перевозок, повышение конкуренции, прежде всего через все большее присутствие иностранных фирм.

\section{2. Литературный обзор}

Согласно проекту закона «О железнодорожном транспорте Украины» [1] одними из основных целей в процессе развития железных дорог являются:

- повышение эффективности деятельности отрасли путем обеспечения безопасности функционирования и доступности рынка услуг железных дорог для всех субъектов хозяйствования;

- создание условий для равного доступа к пользованию услугами объектов инфраструктуры железнодорожного транспорта и дополнительными услугами;

- усовершенствования системы управления железнодорожным транспортом;

- создание благоприятных условий для привлечения инвестиций, необходимых для обновления и модернизации производственно-технической базы железных дорог;

- интеграцию железнодорожного транспорта Украины в европейскую и мировую транспортную системы, создание организационно-правовых, экономических и технико-технологических предпосылок для введения принципов европейской транспортной политики;

- обеспечение прозрачности финансовой деятельности железнодорожного транспорта.

Достижение этих задач не представляется возможным без привлечения частных операторских кампаний, к которым относятся юридические лица или индивидуальные предприниматели, имеющие вагоны, контейнеры на праве собственности или ином праве, участвующие на основе договора с перевозчиком в осуществлении перевозочного процесса с использованием указанных вагонов, контейнеров [2].

Мировому сообществу известно две модели развития железных дорог с негосударственной собственностью.

1. Американская модель, предполагающая наличие нескольких вертикально-интегрированных компаний, оперирующих на своих инфраструктурах, с выделением пассажирских перевозок в отдельную компанию.
2. Европейская модель, предполагающая отделение инфраструктуры от операторов или перевозчиков.

Европейскую модель, в свою очередь, можно разделить на четыре разновидности, обозначив их условно как французскую, шведскую, германскую и английскую. Основные положения реформы:

- железные дороги - жизненно важный элемент транспорта и всего внутреннего рынка Европы, эффективность которого необходимо повышать и который необходимо включить в единый конкурентный рынок;

- железнодорожные Предприятия должны иметь независимый от государства статус и управляться по принципу коммерческих частных компаний. Для них требуется как минимум финансовобухгалтерское разграничение транспортных услуг и обслуживания инфраструктуры;

- государства должны найти способ снизить задолженность государственных компаний - перевозчиков;

- доступ к сети железных дорог должен быть обеспечен для любой компании-перевозчика с соблюдением равных условий. Использование сети сопровождается платой за пользование, которая компания-перевозчик должна перечислять компании, обслуживающей инфраструктуру [3].

Данный документ вывел европейские железные дороги на новый этап развития, тем самым подтолкнув к созданию транспортно-логистических кластеров, причиной этого стало усиление конкуренции на железных дорогах.

Суть кластерного подхода заключается в управлении развитием территории с позиций выстраивания на ней максимально высокой плотности деятельности и максимально длинной цепочки добавленной стоимости. Таким образом, максимизируется экономический эффект и прибыль, которая остается на этой территории и идет на развитие инфраструктуры, тем самым снижая её стоимость для каждого участника кластера. [4] Одной из важнейших особенностей является то, что транспорт и логистика оказывают взаимное влияние на все отрасли промышленности и наоборот. Снижение спроса на продукцию в каких-либо отраслях промышленности ведёт к снижению спроса на услуги транспорта и логистики.[5] И наоборот, низкое качество услуг в сфере транспорта и логистики является сдерживающим фактором для развития всей промышленности региона. В настоящее время качество услуг транспорта в Украине довольно низкое, что обусловлено спадом производства, а также низким уровнем развития инфраструктуры (табл. 1).

Применительно к ТЛК, представляющим собой систему взаимодействующих перевозчиков и клиентов, выбор конкурентной стратегии становления и эффективного функционирования представляет собой особо сложную проблему из-за влияния множества факторов на функционирование предприятий [7]. 
Таблица 1

Уровень развития инфраструктуры в Украине [6]

\begin{tabular}{|c|c|c|c|c|}
\hline Показатель & Рейтинг/27 & $\begin{array}{c}\text { Балл/ } \\
\text { значение }\end{array}$ & $\begin{array}{c}\text { Среднее по } \\
\text { регионам }\end{array}$ & Лучший регион \\
\hline $\begin{array}{c}\text { Энергетическая и телекоммуникационная } \\
\text { инфраструктура }\end{array}$ & 5 & 5,1 & 4,55 & 6.04 Киев \\
\hline Транспортная инфраструктура & 5 & 3,8 & 3,26 & 4.19 Киев \\
\hline Колличество телефонных линий & 6 & 26,0 & 24,31 & 67.97 Одесская \\
\hline Качество электроснабжения & 2 & 5,2 & 4,74 & 5.22 Ровенская \\
\hline Качество железнодорожной инфраструктуры & 1 & 5,5 & 4,85 & 5.51 Харьковская \\
\hline Качество инфраструктуры в целом & 1 & 4,9 & 4,41 & 4.91 Харьковская \\
\hline Качество инфраструктуры авиаперевозок & 3 & 5,1 & 3,09 & 5.73 Киев \\
\hline Качество портовой инфраструктуры & 11 & 2,6 & 2,83 & 5.06 Одесская \\
\hline
\end{tabular}

\section{3. Цели и задачи исследования}

Цель исследования - выявление основных принципов создания транспортно-логистических кластеров в Украине.

Для достижения поставленной цели была построена схема создания транспортно-логистического кластера, выделены основные принципы создания ТЛК; определены основные критерии классификации участников кластера.

\section{4. Построение схемы создания ТЛК}

Транспортно-логистический кластер является наиболее современным подходом к организации транспортной сферы в регионе. ТЛК представляет собой объединение отдельных регионально, функци- онально и экономически связанных между собой логистических звеньев: международных транспортных коридоров, транспортных узлов магистральной инфраструктуры, транспортно-распределительных логистических центров, магистральных, региональных и локальных путей сообщения в единую систему перевозочного процесса, способную предоставить качественный логистический сервис внутренним или внешним потребителям при минимизации общих логистических издержек. Территориальный охват кластера может варьироваться от одного города или области (региона) до страны или даже нескольких соседствующих стран.

Алгоритм создания кластера (рис. 1) включает в себя следующие этапы.

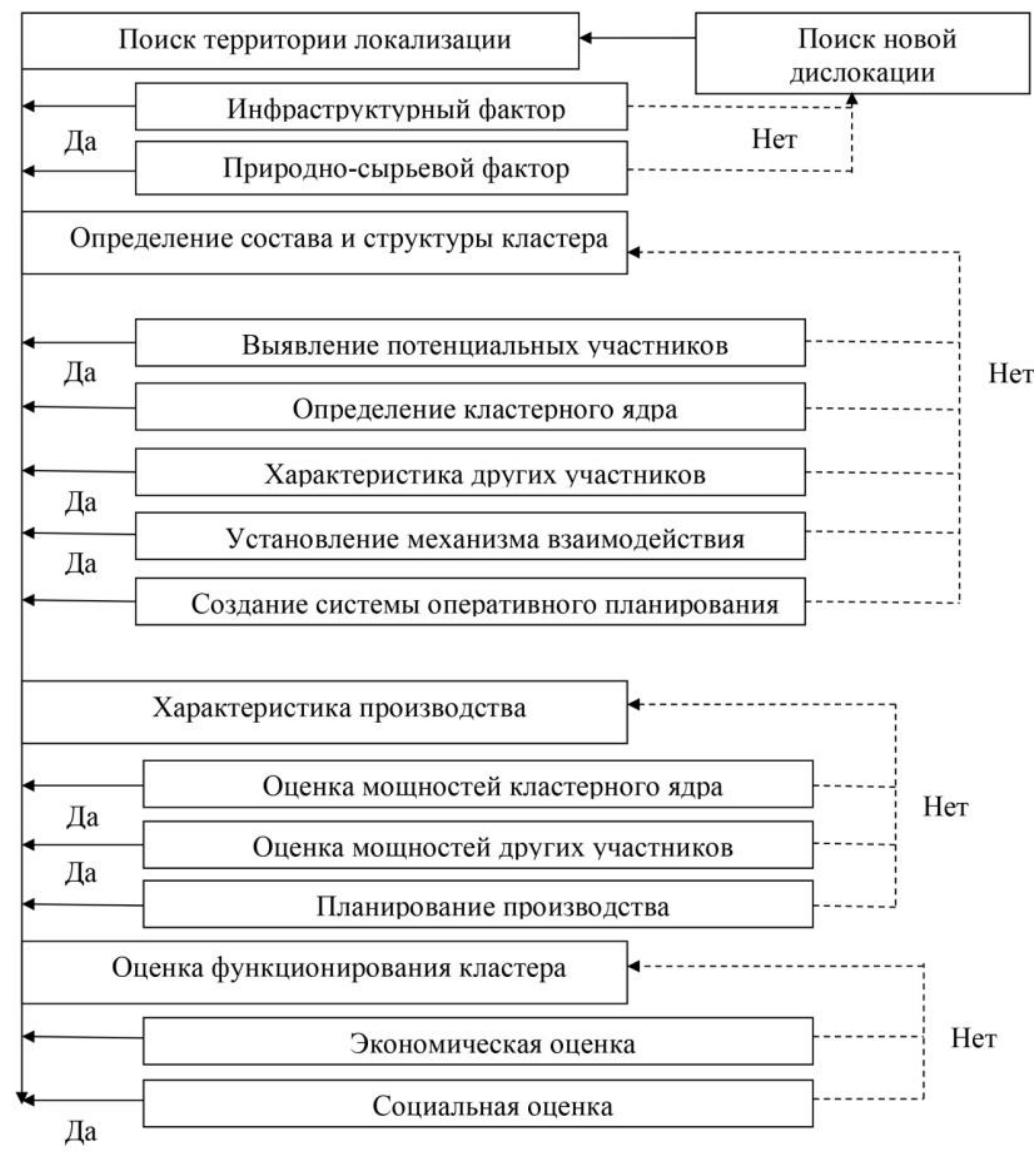

Рис. 1. Схема создания транспортно-логистического кластера 
1. Поиск территории локализации - географическая составляющая кластера включающая в себя группу объектов на определенной территории деятельность которых соответствует задачам кластера. Включает в себя общую оценку объектов.

2. Определение состава кластера. Данный этап включает выявление ядра - самого экономически развитого объекта в регионе, оценка связей кластерного ядра с другими потенциальными участниками. Немаловажным является фактор доступности предприятий входящих в ядро.

3. Установление предполагаемых связей и механизма взаимодействия между участниками. Данный этап включает в себя поиск критериев для установления сотрудничества между участниками кластера на относительно взаимовыгодных условиях.

4. Оценка функционирования проводиться для получения прогнозированного результата от синергетического эффекта в общем и для каждого из участников.

Работая в кластерной среде нельзя рассчитывать исключительно на сотрудничество. Одним из основных полезных свойств кластера является наличие конкурентной борьбы. В процессе существования и функционирования ядро кластера может неоднократно меняться [9].

При классификации участников ТЛК следует учитывать специфику работы в регионе: вид транспорта, географические особенности, преимущественное количество и объем груза в среднем принимаемого к перевозке, расположение и вид деятельности отправителей и получателей. Прежде всего, от классификации участников зависит как вид кластера создается - региональный, портовой, пограничный [10].

\section{5. Определение критериев классификации} участников кластера

Критерий доступности: определяется легкостью в составлении документации, количеством рекламы, объемом сети приема заказов, объектов приема и выдачи груза. Как правило, данный параметр определяется отношением количества поступивших заявок к количеству выполненных:

$$
D=\frac{D_{p}}{D_{v}} .
$$

Критерий функциональности: определяется как мощность и количество оборудования, подвижного состава, его характеристика, наличие и выполнения графика перевозки, умение оперативно реагировать на изменения в процессе доставки. Данный критерий определяется как сумма полезной работы, выполненной мощностями производства. Предположительно для транспортно-складского предприятия в общем виде:

$$
A=A_{p s}+A_{s k}+A_{p r}
$$

где $A_{p s}$ - полезная работа при использовании подвижных единиц, грн.; $A_{s k}$ - полезная работа складских мощностей, грн.; $A_{p r}$ - полезная работа прочих мощностей, доступных предприятию (дис- петчерский центр, транспортно-экспедиционный отдел и т. д.), грн.

Критерий надежности - это показатель качества выполненной полезной работы, который зависит, прежде всего, от вероятности потери количества и качества груза принятого к выполнению с ним определенного числа операций. При определении данного критерия следует обратить внимание на потерю прибыли клиента в случае наступления негативных ситуаций (уменьшение объема груза, потеря качества, несвоевременность доставки, дополнительные затраты, штрафные санкции и т. д.).

$$
N=\sum_{i=1}^{n} P_{f}(C)
$$

где $N$ - критерий качества, грн.; $\sum_{i=1}^{n} P_{f}(C)$ - сумма наступивших негативных последствий в процессе перевозки и хранения, приведших к уменьшению прибыли сторон.

\section{6. Выводы}

Сформированные на основании предложенных принципов транспортно-логистические кластеры позволят в перспективе с учетом региональных особенностей обеспечить конкурентоспособность отечественных перевозчиков, дополнительную защиту от влияния заграничных фирм. Отбор и классификация по приведенным критериям позволят сформировать кластерное объединение с учетом особенностей функционирования каждого из участников.

\section{Литература}

1. Закон України "Про залізничний транспорт України" [Текст]. - Міністерство інфраструктури України, 2015. - Режим доступу: http://mtu.gov.ua/news/ 200.html? PrintVersion

2. Оператор железнодорожного подвижного состава [Электронный ресурс]. - АКАДЕМИК. - Режим доступа: http://official.academic.ru/

3. Европейская реформа железных дорог - основные этапы и основные документы [Электронный ресурс]. Железные дороги Мира. - Режим доступа: http:// $1430 \mathrm{~mm} . \mathrm{ru} /$ node $/ 213$

4. Альошинський, Є. С. Стратегія розвитку регіональної транспортної системи на базі формування ТЛК Харківської області [Текст] / С. С. Альошинський. - Харків: Департамент інноваційного розвитку промисловості і транспортної структури, 2012. - 17 с.

5. Зарубежный опыт структурных реформ на железнодорожном транспорте [Электронный ресурс]. - Best Referat.ru. - Режим доступа: http://www.bestreferat. ru/referat109381.html

6. Конкуретноспособная Украина [Электронный ресурс]. - Фонд «Эффективное управление». - Режим доступа: http://www.feg.org.ua/indexes/

7. Цихан, Т. В. Кластерная теория экономического развития [Электронный ресурс] / Т. В. Цихан // Теория и практика управления. - 2003. - № 5. - Режим доступа: http://www. subcontract.ru/Docum/DocumShow_DocumID_168.html

8. Транспортно-логистические кластеры в Европейском Союзе [Электронный ресурс]. - Режим доступа: http://innocentr-samara.ru/files/Transportno-logisticheskie\% 20 klastery\%20v\%20ES.pdf

9. Транспортно-логистический кластер в Самарской области [Электронный ресурс]. - Режим доступа: http:// www.protown.ru/russia/obl/articles/articles_1073.html 
10. Алешинский, Е. С. Повышение конкуретноспособности железнодорожного транспорта за счет создания транспортно-логистических кластеров [Текст] / Е. С. Алешинский, В. В. Мещеряков, И. А. Лапушкин, Е. И. Рябовол // Восточно-Европейский журнал передовых технологий. - 2013. - Т. 5, № 3 (65). - С. 39-45. - Режим доступа: http://journals.uran.ua/eejet/article/view/18500

\section{Referenses}

1. The law of Ukraine "On railway transport" (2015). The Ministry of infrastructure of Ukraine. Available at: http://mtu.gov.ua/news/200.html?PrintVersion

2. Operator of railway rolling stock. ACADEMICIAN. Available at: http://official.academic.ru/

3. European railway reform - the main stages and key documents. Railways of the World. Available at: http:// 1430mm.ru/node/213

4. Alyoshinsky, E. S. ( 2012). The development strategy of regional transport systems on the basis of the formation of TLK Kharkiv region. Kharkiv: Department of innovative development of industry and transport structure, 17.
5. International experience of structural reforms in railway transport. BestReferat.ru. Available at: http://www. bestreferat.ru/referat-109381.html

6. Competitive Ukraine. Foundation "Effective Management". Available at: http://www.feg.org.ua/indexes/

7. Tsikhan, T. (2003). The cluster theory of economic development. Theory and practice of management, 5. Available at: http://www.subcontract.ru/Docum/DocumShow_DocumID_ 168.html

8. Transport and logistics clusters in the European Union. Available at: http://innocentr-samara.ru/files/Transportnologisticheskie\%20klastery\%20v\%20ES.pdf

9. Transport and logistics cluster in the Samara region. Available at: http://www.protown.ru/russia/obl/articles/articles_ 1073.html

10. Aleshynskyj, E. S., Meshherjakov, V. V., Lapushkyn, Y. A., Rjabovol, E. Y. (2013). Increasing of rail transport competitiveness by forming transportation and logistics clusters. Eastern-European Journal Of Enterprise Technologies, 5/3 (65), 39-45. Available at: http://journals.uran.ua/eejet/article/ view/18500

Дата надходження рукопису 11.08.2016

Алешинский Евгений Семенович, доктор технических наук, заведующий кафедры, кафедра транспортных систем и логистики, Украинский государственный университет железнодорожного транспорта, пл. Фейербаха, 7, г. Харьков, Украина, 61001

E-mail: aes-upp@mail.ru

Мещеряков Василий Владимирович, аспирант, кафедра транспортных систем и логистики, Украинский государственный университет железнодорожного транспорта, пл. Фейербаха, 7, г. Харьков, Украина, 61001

E-mail: vasyan98@ukr.net

Биловус Людмила Вячеславовна, Украинский государственный университет железнодорожного транспорта, пл. Фейербаха, 7, г. Харьков, Украина, 61001

UDC 331.47:377.44

DOI: 10.15587/2313-8416.2016.78573

\title{
POST-GRADUATE EDUCATION OF RESPONSIBLE STAFF ON LABOUR PROTECTION: PROBLEMS AND FEATURES
}

\author{
(C) R. Pahomov, E. Dyachenko, O. Zyma
}

The paper discusses the main problems of post-graduate education of managers and engineers and technical workers on labour protection. The necessity of responsible persons' studying is grounded. The effect of studying by staff and officials on labour protection problems in the workplace is reviewed. Structural and functional bases of studying of officials are studied. Analysis of the characteristics of the educational process is conducted. Different approaches and methods of studying are considered. Principles, the use of which can increase the efficiency of the studying process during the studying in the expert technical centers, are offered Keywords: advanced training, staff, studying process, principles of studying, labour protection

У статті розглядаються основні проблеми післядипломної освіти інженерно-технічних співробітників та керівників з питань охорони праці. Обумовлено необхідність навчання відповідних працівників. Розглянуто ефект проходження навчання співробітників та посадових осіб з питань охорони праці на робочому місиі. Досліджені структурні і функціональні засади навчання посадових осіб. Виконано аналіз характеристики освітнього процесу. Розглянуто різні підходи і методи навчання. Наведені принципи, використання яких може підвищити ефективність навчального процесу при навчанні в експертнотехнічних ичентрах

Ключові слова: підвищення кваліфікащії, персонал, навчальний процес, принципи навчання, охорона праџฺі 